\title{
ANTITUBERCULOSIS ACTIVITY OF EXTRACT AND FRACTIONS OF TINOSPORA CRISPA AGAINST MYCOBACTERIUM TUBERCULOSIS H37RV USING MYCOBACTERIA GROWTH INDICATOR TUBE AND AGAR PROPORTION METHOD
}

\section{RETNO WAHYUNINGRUM ${ }^{1,2}$, RITMALENI ${ }^{1 *}$, TATANG IRIANTI ${ }^{1}$, SUBAGUS WAHYUONO ${ }^{1}$, TAKUSHI KANEKO ${ }^{3}$}

${ }^{1}$ Department of Pharmaceutical Chemistry, Faculty of Pharmacy, Universitas Gadjah Mada, Indonesia. ${ }^{2}$ Department of Biology Pharmacy, Faculty of Pharmacy, Universitas Muhammadiyah Purwokerto, Indonesia. ${ }^{3}$ Tuberculosis Alliance, New York, United States. Email: ritmaleni@ugm.ac.id

\author{
Received: 15 September 2017, Revised and Accepted: 30 November 2017
}

ABSTRACT

Objective: The increasing incidence of multidrug-resistant tuberculosis (TB) has created a need to discover a new anti-TB drug candidates. The aim of this study was to screen extract and fractions of Tinospora crispa for activity against Mycobacterium tuberculosis H37Rv.

Methods: The dried and pulverized T. crispa stem was extracted by maceration method using ethanol (96\%). The anti-TB activity was carried out using mycobacteria growth indicator tube (MGIT) system and agar proportion method with Lowenstein-Jensen (LJ) medium.

Result: The result of this study showed that ethanolic extract and fractions of $T$. Crispa did not exhibit anti-TB activity in the range of $100-1000 \mu \mathrm{g} / \mathrm{ml}$ with MGIT method, while with agar proportion method, there were $M$. tuberculosis colonies growth on the LJ containing $1000 \mu \mathrm{g} / \mathrm{ml}$ extract slants.

Conclusion: The tested extract and fractions of T. crispa have no anti-TB activity against M. tuberculosis until $1000 \mu \mathrm{g} / \mathrm{ml}$.

Keywords: Mycobacterium tuberculosis, Tinospora crispa, Tuberculosis activity.

(C) 2018 The Authors. Published by Innovare Academic Sciences Pvt Ltd. This is an open access article under the CC BY license (http://creativecommons. org/licenses/by/4. 0/) DOI: http://dx.doi.org/10.22159/ajpcr.2018.v11i3.22587

\section{INTRODUCTION}

Tuberculosis (TB) is an infectious disease that causes most widely death in the world [1]. In 2014, TB caused 1.5 million of deaths [2]. It remains a major global health problem. This disease is caused by Mycobacterium tuberculosis, an intracellular obligate and aerobic bacillus that multiplies within macrophage. M. tuberculosis infects the lungs and can spread to other human through droplets from the throat of people-infected TB. Beside of the lungs, this bacteria can affect other organs in the human body such as lymph gland, abdomen, skin, joints, and meninges.

TB occurs in every part of the world. In low- and middle-income countries, TB cases occurred over 95\% [3]. About 58\% of reported TB cases in the world occurred in Southeast Asia and West Pacific [2]. Indonesia becomes the second country in the world with the largest TB cases. In the global TB report of the year 2015, the WHO informed that there were 9.6 million TB cases and $12 \%$ of new cases were coinfected with HIV.

TB is a curable disease with a combination of four first-line drugs: Isoniazid, rifampicin, pyrazinamide, and ethambutol, for a regimen of at least 6-9 months. Unfortunately, in the past few decades, multidrugresistant TB (MDR-TB) was arised. MDR-TB is caused by strain of M. tuberculosis that is resistant to isoniazid and rifampicin [4]. The resistance is caused by mutation in the nucleic acid of the bacteria. For assessing bacterial resistance, molecular detection technique is known fast and specific [5]. In 2014, there were 480.000 MDR-TB cases and estimated 190.000 people are died because of this disease [2]. Patients' adherence to TB treatment is important to get the effective treatment and to prevent the occurrence of multidrug-resistant MDRTB [6]. Approximately $10 \%$ of the total MDR-TB cases are classified as extensively drug-resistant TB (XDR-TB) [7]. In these cases, M. tuberculosis strain is not only resistant to isoniazid and rifampicin but also resistant to any fluoroquinolones and to at least first-line injectable anti-TB drug, i.e, amikacin, capreomycin, and kanamycin. The emergence of MDR-TB and followed by XDR-TB remains a major challenge to global health. This condition led to an urgent need to discover new anti-TB drugs. Many research is focused on the discovery and development of new anti-TB drug from natural product [1]. The discovery of new anti-TB drug candidates who are more effective against MDR-TB strain and XDR-TB strain became very urgent, especially in developing countries with high incidence of TB. It can be done by screen from novel compound from natural product including plant species [8]. Medicinal plants can be potential anti-TB drug candidate if it is proven by scientific studies first. Some of them used as food ingredient, and it will be more efficient to minimize the disease [9]. Not only plants but also other natural product can be used as a source of new anti-TB agents. Crude extract from a Bacillus sp. N strain associated with entomopathogenic nematode Rhabditis (Oscheius) sp. has antimycobacterial activity against $M$. tuberculosis $\mathrm{H} 37 \mathrm{Rv}$ with a MIC of $125 \mu \mathrm{g} / \mathrm{ml}$ [10].

Tinospora crispa (L.) Miers ex Hook. f. Thoms is a member of Menispermaceae. It is popularly known as Brotowali in Indonesia. It is widely distributed over tropical and subtropical Asia including India, Thailand, Vietnam, Philippines, Indonesia, and Malaysia [11]. This plant is widely used as traditional medicine, especially its stem. The stem of T. crispa is traditionally used to treat TB. Some preliminary research reported the activity of $T$. crispa against $M$. tuberculosis. Ethanolic extract of T. crispa from Laos has antimycobacterial activity against M. tuberculosis with minimum inhibitory concentration (MIC) 2.43-96.2 $\mu \mathrm{g} / \mathrm{ml}$ [12]. However, there has been no report about the antimycobacterial activity of T. crispa that grows in Indonesia and its fractions or isolates. The present study determined the antimycobacterial activity of ethanolic extract and fractions of T. crispa collected from Indonesia.

\section{MATERIALS AND METHODS}

Materials

The stem of T. crispa was collected in February 2016 from Sleman, Yogyakarta, Indonesia, and was authenticated in the Department of 
Pharmaceutical Biology, Faculty of Pharmacy, Gadjah Mada University. The stem was dried at $40^{\circ} \mathrm{C}$ in a drying cabinet and was ground with grinding machine before extraction. Each sample was dissolved in dimethyl sulfoxide 4\% (Sigma-Aldrich Chemical). M. tuberculosis H37Rv used in this study was collected from Balai Besar Laboratorium Kesehatan, East Java (Indonesia). Middlebrook (MB) 7 H9 broth (Difco), oleic acid/albumin/dextrose/catalase enrichment (OADC) (BectonDickinson and Company), Polymixin B, Amphotericin B, Nalidixic Acid, Trimethoprim, Azlocillin (Becton-Dickinson and Company), Tween 80 (Sigma-Aldrich Chemical), Isoniazid (Sigma-Aldrich Chemical), Rifampicin (Sigma-Aldrich Chemical), and Kit MGIT BD Biosciences (Becton-Dickinson Company) were used. Lowenstein-Jensen (LJ) medium was prepared following the standard operating procedures recommended by the Indonesian National TB Program [13], which are in line with the WHO guidelines [14].

\section{Extraction}

Dried and ground plant material $(500 \mathrm{~g})$ was extracted by maceration method with ethanol $96 \%$ and repeated twice. The extracts were then condensed using a Buchi rotary evaporator (rotavapor).

\section{Fractionation}

Dried and ground plant material (500 g) was extracted by maceration method with ethanol $96 \%$ and repeated twice. The extracts were then condensed using a Buchi rotary evaporator (rotavapor) yielded $136.6 \mathrm{~g}$ thick extract. The extract was fractionated using trituration method. The ethanolic extract ( $25 \mathrm{~g}$ ) added with $\mathrm{n}$-hexane and then shaked for $10 \mathrm{~min}$. After shaking, it filtered with Sinterglass, and then, the filtrate was collected. The fractionation with $n$-hexane was conducted 3 times. The collected filtrate condensed using a rotavapor and yielded $n$-hexane fraction, FH (10 g). The residue was called n-hexane-insoluble fraction, FTH (15 g). Five gram (5 g) of FTH then added with ethyl acetate and then shaked for $10 \mathrm{~min}$. After shaking, it filtered with Sinterglass, and then, the filtrate was collected. The fractionation with ethyl acetate was conducted 3 times. The collected filtrate condensed using a rotavapor and its called ethyl acetate fraction, FEA (2.2 g). The residue was called ethyl acetate-insoluble fraction, FTEA $(2.8 \mathrm{~g})$.

\section{MGIT anti-TB test}

In this study, M. tuberculosis $\mathrm{H} 37 \mathrm{Rv}$ was used. M. tuberculosis was cultured on the mycobacteria growth indicator tube (MGIT) with BACTEC MGIT 960 growth supplement. MGIT 960 instrument (Becton Dickinson Diagnostic Systems, Sparks, Maryland, USA) system was used in this study to evaluate antimycobacterial activity of extract and its fractions against M. tuberculosis H37Rv. Before inoculating with the bacteria, MGIT growth tubes containing $7 \mathrm{ml}$ media $\left(\mathrm{BBL}^{\mathrm{m}} \mathrm{MGIT}\right.$ 'mactec and Dickinson, USA) were supplemented with MB growth supplement (Oleic acid, Albumin, Dextrose, Catalase; OADC) as specified in the manufacturer's protocol $(800 \mu \mathrm{l} /$ tube $)$. After adding the growth supplement, $100 \mu$ aliquots of extract or fraction were added aseptically into the MGIT tubes at different concentrations. For inoculation, the bacterial stock was thawed and prepared in 7H9-S media so that the inoculation volume $(500 \mu \mathrm{l})$ contained sufficient numbers of bacterial cell $\left(1 \times 10^{5} \mathrm{cfu} / \mathrm{ml}\right.$ in a tube). The contents were mixed gently by inverting the tube 3-4 times. All inoculated tubes were then inserted into the MGIT 960 automated culture system after scanning the barcode and incubated at the temperature of $37^{\circ} \mathrm{C}$. For positive control, isoniazid, rifampicin, or no drugs were used. The growth control (GC) tube was prepared by adding $800 \mu \mathrm{l}$ growth supplement and $500 \mu \mathrm{l}$ bacterial suspension into MGIT tube. The GC did not contain any samples. In the case of positive growth, the system automatically detects growth and signals positive. After a maximum of 6 weeks (42 days), the instrument flags a tube as negative if no growth occurs. The results are qualitative such as susceptible (S), resistant (R), or indeterminate (X). The instrument interprets results at the time when the growth unit (GU) in GC reaches 400. At this point, the GU values of the drug vial are evaluated: Susceptible when the GU of the drug tube is $<100$ and resistant when the GU of the drug tube is 100 or more. Further, $\mathrm{X}$ results when certain conditions occur which may affect the test, such as GU of the control reaches $>400$ in $<4$ days [15].

\section{Anti-TB test with agar proportion method}

Anti-TB test with agar proportion method using LJ media was carried out to confirm the MGIT result. For this purpose, $1 \mathrm{ml}$ of extract and $100 \mu \mathrm{l}$ of M. tuberculosis H37Rv suspension were added into MB 7H9. After 2 days of incubation, $100 \mu$ l of the mixture was subcultured onto LJ slants. Then, it was incubated for $4-6$ weeks at $37^{\circ} \mathrm{C}$. The growth of the mycobacterial colonies (rough, tough, and buff-colored) was inspected. The mycobacterial colonies on the LJ slants indicated that the extract cannot inhibit the mycobacterial growth.

\section{RESULTS}

The results of anti-TB assay of extract and its fractions against M. tuberculosis $\mathrm{H} 37 \mathrm{Rv}$ are shown in Table 1. These results showed that from T. crispa extract and fractions tested, none of them exhibited anti-TB activity against $M$. tuberculosis H37Rv up to $1000 \mu \mathrm{g} / \mathrm{ml}$. This was contradictive with the result of previous research that ethanolic extract of T. crispa from Laos has antimycobacterial activity against M. tuberculosis with MIC $2.43-96.2 \mu \mathrm{g} / \mathrm{ml}$. The antimycobacterial activity that used in the research was microplate Alamar blue assay. The difference of method used in this research and previous research could be one of the reasons for this different results. Time for obtaining results was 9 days.

To confirm the MGIT results, anti-TB activity of T. crispa ethanolic extract was tested with agar proportion method. There were 3 concentrations tested: 1000,500 , and $250 \mu \mathrm{g} / \mathrm{ml}$. There was M. tuberculosis colony growth on the LJ containing extract slants. It was compared to M. tuberculosis slant $(\mathrm{K}+)$ and they showed the same appearance of

Table 1: Antimycobacterial activity results of T. crispa ethanolic extract and its fraction using MGIT system

\begin{tabular}{|c|c|c|c|c|c|}
\hline No & Sample & Code & Concentration $(\mu \mathrm{g} / \mathrm{ml})$ & Growth unit & Result \\
\hline \multirow[t]{3}{*}{1} & Ethanolic extract of T. crispa stem & EEB & 1000 & 400 & Not active \\
\hline & & & 500 & 400 & Not active \\
\hline & & & 100 & 400 & Not active \\
\hline \multirow[t]{3}{*}{2} & n-hexane-soluble fraction & FH & 1000 & 400 & Not active \\
\hline & & & 500 & 400 & Not active \\
\hline & & & 100 & 400 & Not active \\
\hline \multirow[t]{3}{*}{3} & $\mathrm{n}$-hexane-insoluble fraction & FTH & 1000 & 400 & Not active \\
\hline & & & 500 & 400 & Not active \\
\hline & & & 100 & 400 & Not active \\
\hline \multirow[t]{3}{*}{4} & Ethyl acetate-soluble fraction & FEA & 1000 & 400 & Not active \\
\hline & & & 500 & 400 & Not active \\
\hline & & & 100 & 400 & Not active \\
\hline \multirow[t]{3}{*}{5} & Ethyl acetate-insoluble fraction & FTEA & 1000 & 400 & Not active \\
\hline & & & 500 & 400 & Not active \\
\hline & & & 100 & 400 & Not active \\
\hline
\end{tabular}

T. crispa: Tinospora crispa, MGIT: Mycobacteria growth indicator tube 
the slants. As shown in Fig. 1, the positive control slant which contains rifampicin as anti-TB drug showed that there are no yellow colonies of M. tuberculosis. The results of this test showed that T. crispa ethanolic extract up to $1000 \mu \mathrm{g} / \mathrm{ml}$ did not exhibited anti-TB activity.

\section{DISCUSSION}

T.crispa is a well-known source of herbal plant which is used traditionally as medications for diabetes mellitus, hypercholesterolemia, and also hepatoprotective [16]. Ethanolic extract of T. crispa stem showed general standardization parameters. This plant has the potential compounds to be developed as a raw material of standardized herbal medicine [17]. To screen the potentiality of T. crispa as anti-TB candidate, ethanolic extract of the stem of T. crispa was tested against $M$. tuberculosis using MGIT system. Bactec MGIT 960 - an automated liquid system - has been developed to reduce time of experiment [18]. It is much shorter than agar proportion method (turnaround time is around 21 days). MGIT 960 system is a reliable, rapid, automated method for testing the susceptibility of clinical M. tuberculosis isolates to the firstline drugs [19]. Time for obtaining results in this research was 9 days, and it is longer than that observed by Kontos et al. (2004). It needed 7.12 days to obtain the MGIT results.

Different culture media are used for the isolation of mycobacteria. The most common is LJ medium, an egg-based medium. LJ medium contains high concentrations of malachite green to prevent contamination with other bacteria. However, culture on it is long ( 3 weeks to 3 months for M. tuberculosis) and time-consuming. MGIT was better than LJ medium in recovery rate and detection time of mycobacterial growth [20]. Due to its sensitivity, MGIT should be used for smear-negative pulmonary TB patients [21]. MGIT system could be an acceptable alternative to the radiometric Bactec method for rapid and reliable testing of M. tuberculosis [22].

The MGIT consists of liquid broth medium that is known to yield better recovery and faster growth of mycobacteria. The MGIT contains modified Middlebrook 7 H9 broth base. The MGIT tube contains an oxygen-quenched fluorochrome, tris 4,7-diphenyl-1, 10-phenanthroline ruthenium chloride pentahydrate, embedded in silicone at the bottom of the tube. During bacterial growth within the tube, the free oxygen is used and is replaced with carbon dioxide. The decrease of free oxygen made the fluorochrome was no longer inhibited and produces a fluorescence within the MGIT tube when visualized under UV light [20].

The relative growth ratio between the sample-containing tube and sample-free GC tube was determined by the system's software algorithm, once the GC became positive. If the relative growth of the sample containing tube was equal to or exceeded that of the GC tube, the bacterial was considered resistant; if the relative growth was less than in the GC tube, the bacterial was considered susceptible. The instrument did the final interpretation and reported the result automatically.

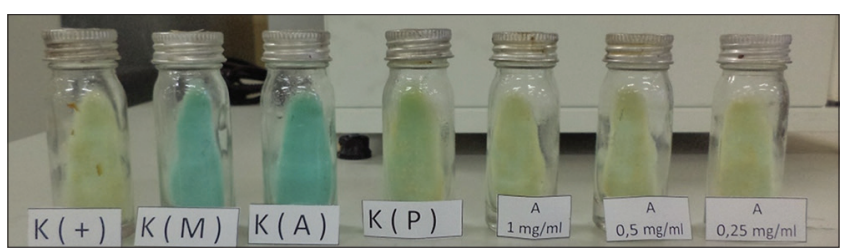

Fig. 1: Tinospora crispa ethanolic extract which has been inoculated with Mycobacterium tuberculosis on LowensteinJensen medium slant at $37^{\circ} \mathrm{C}$ for 4 weeks. (a) M. tuberculosis control; (b) medium control (without $M$. tuberculosis suspension); (c) positive control, rifampicin $40 \mu \mathrm{g} / \mathrm{ml}$; (d) solvent control (dimethyl sulfoxide 5\%); (e) T. crispa ethanolic extract of concentration $1000 \mu \mathrm{g} / \mathrm{ml}$; (f) T. crispa ethanolic extract of concentration $500 \mu \mathrm{g} / \mathrm{ml}$; (g) T. crispa ethanolic extract of concentration $250 \mu \mathrm{g} / \mathrm{ml}$
There are many different references to analyze the anti-TB activity of plant extracts. In the previous study, plant extract was considered active against $M$. tuberculosis if MIC was $<100 \mu \mathrm{g} / \mathrm{ml}$ [23-25], $<200 \mu \mathrm{g} / \mathrm{ml}[26,27],<1600 \mu \mathrm{g} / \mathrm{ml}[28]$, and $\leq 2048 \mu \mathrm{g} / \mathrm{ml}[29]$. In other paper, the antimicrobial activity of plant extracts was classified as significant (MIC $\leq 100 \mu \mathrm{g} / \mathrm{ml}$ ), moderate $(100<$ MIC $<625 \mu \mathrm{g} / \mathrm{ml}$ ), or weak (MIC $>625 \mu \mathrm{g} / \mathrm{ml}$ ) [30]. In this study, we tested extract and fraction of T. crispa at three concentration with $1000 \mu \mathrm{g} / \mathrm{ml}$ as the highest concentration. Hence, we interpreted activity as inhibition at any values of MIC $\leq 1000 \mu \mathrm{g} / \mathrm{ml}$.

Agar proportion method with LJ medium was conducted due to confirm the results of anti-TB activity test with MGIT method. This method is the current standard method used in Indonesia for drug susceptibility testing of M. tuberculosis against anti-TB drugs. It is required at least 28 days for obtaining the results, and this is the drawback of this method. Mycobacterial growth on cultures was considered as positive as soon as yellow colonies appear on LJ medium. In this test, we used three concentration series, i.e., 1000,500 , and $250 \mu \mathrm{g} / \mathrm{ml}$. The results of this test showed that T. crispa ethanolic extract up to $1000 \mu \mathrm{g} / \mathrm{ml}$ did not exhibited anti-TB activity. This results obtained an agreement between the MGIT method and the agar proportion method with LJ medium.

Ethanolic extract of Brotowali stem contains flavonoid as a group of compounds that have antiradical activity. It has DPPH radical scavenging activity with $\mathrm{IC}_{50}$ was $33.75 \mu \mathrm{g} / \mathrm{ml}$ [31]. T. crispa contains a wide range of secondary metabolites such as alkaloids, terpenes, flavones, and phenolics [32]. This compounds exhibited antitubercular activity $[25,33]$. However, in this research, we did not do any test to find what compounds are in T. crispa extract and fractions.

\section{CONCLUSIONS}

Our data show that ethanolic extract and fractions of T. crispa have no anti-TB activity against $M$. tuberculosis until $1000 \mu \mathrm{g} / \mathrm{ml}$.

\section{ACKNOWLEDGMENTS}

The authors would like to thank Tuberculosis Alliance and Faculty of Pharmacy, Universitas Gadjah Mada, for the funding of this research.

\section{AUTHORS CONTRIBUTION}

All the author have contributed equally.

\section{CONFLICTS OF INTERESTS}

We have no conflict of interest to declare

\section{REFERENCES}

1. Chinsembu KC. Tuberculosis and nature's pharmacy of putative antituberculosis agents. Acta Trop 2016;153:46-56.

2. World Health Organization. Global Tuberculosis Report 2015. Geneva: World Health Organization; 2015.

3. Bhunia SK, Sarkar M, Banerjee A, Giri B. An update on pathogenesis and management of tuberculosis with special reference to drug resistance. Asian Pac J Trop Dis 2015;5:673-86.

4. Keshavjee S, Farmer PE. Tuberculosis, drug resistance, and the history of modern medicine. N Engl J Med 2012;367:931-6.

5. Syaifudin M, Septiani D. Analysis of the resistance of M. tuberculosis to fluoroquinolon and the implementation of nuclear based biomolecular technique. Indones J Pharm 2011;22:120-7.

6. Perwitasari DA, Noverliyanti M, Darmawan E, Mulyani AU, Atthobari J, Wilffert B. Genotype polymorphisms of Nat2 and Cyp2e1 genes associated with drug induced liver injury (Dili) in Indonesian tuberculosis patients. Indones J Pharm 2016;27:22-7.

7. Sotgiu G, Migliori GB. Facing multi-drug resistant tuberculosis. Pulm Pharmacol Ther 2015;32:144-8.

8. Alvin A, Miller KI, Neilan BA. Exploring the potential of endophytes from medicinal plants as sources of antimycobacterial compounds. Microbiol Res 2014;169:483-95.

9. Dhanabal SP, Lall N, Pavithra N, Chaitanya MV. Natural products as an important leads for discovery of new antitubercular agents: A review. 
Int J Pharm Pharm Sci 2015;7:2-7.

10. Sreerag RS, Dileep C, Kumar SN. Antimycobacterial activity of crude extracts produced by Bacillus $\mathrm{Sp}$. associated with entomopathogenic nematode. Int J Pharm Pharm Sci 2014;6:140-2.

11. Chang CC, Ho SL, Lee SS. Acylated glucosylflavones as $\alpha$-glucosidase inhibitors from Tinospora crispa leaf. Bioorg Med Chem 2015;23:3388-96

12. Elkington BG, Sydara K, Newsome A, Hwang CH, Lankin DC, Simmler $\mathrm{C}$, et al. New finding of an anti-TB compound in the genus marsypopetalum (Annonaceae) from a traditional herbal remedy of Laos. J Ethnopharmacol 2014;151:903-11.

13. Ministry of Health Republic of Indonesia. Guideline for Culture, Identification and Sensitivity Test of Mycobacterium tuberculosis from Respiratory Tract; 2012.

14. Narvaiz I, Kim KS, Frieden T, Laszlo A, Luelmo F, Norval PY, et al. Laboratory Services in Tuberculosis Control. Geneva Switz: WHO; 1998.

15. Siddiqi S, Ahmed A, Asif S, Behera D, Javaid M, Jani J, et al. Direct drug susceptibility testing of Mycobacterium tuberculosis for rapid detection of multidrug resistance using the bactec MGIT 960 system: A multicenter study. J Clin Microbiol 2012;50:435-40.

16. Abu MN, Samat S, Kamarapani N, Nor Hussein F, Wan Ismail WI, Hassan HF. Tinospora crispa ameliorates insulin resistance induced by high fat diet in wistar rats. Evid Based Complement Alternat Med 2015;1-6.

17. Harwoko H, Choironi NA. Quality standardization of brotowali (Tinospora crispa) stem extract. Tradit Med J 2016;21:6-11.

18. López-Roa P, Ruiz-Serrano MJ, Alcalá L, García-Escribano Ráez N, García de Viedma D, Bouza E, et al. Susceptibility testing to secondline drugs and ethambutol by genoType MTBDRsl and bactec MGIT 960 comparing with agar proportion method. Tuberculosis (Edinb) 2012;92:417-21.

19. Kontos F, Maniati M, Costopoulos C, Gitti Z, Nicolaou S, Petinaki E, et al. Evaluation of the fully automated bactec MGIT 960 system for the susceptibility testing of Mycobacterium tuberculosis to first-line drugs: A multicenter study. J Microbiol Methods 2004;56:291-4.

20. Essawy TS, Saeed AM, Fouad NA. Comparative study between using lowenstein jensen, Bio-FM media and mycobacteria growth indicator tube (MGIT) system in identification of Mycobacterium tuberculosis. Egypt J Chest Dis Tuberc 2014;63:377-84.

21. Srisuwanvilai LO, Monkongdee P, Podewils LJ, Ngamlert K, Pobkeeree V, Puripokai P, et al. Performance of the BACTEC MGIT
960 compared with solid media for detection of mycobacterium in Bangkok, Thailand. Diagn Microbiol Infect Dis 2008;61:402-7.

22. Zapata P, Arbeloa M, Aznar J. Evaluation of mycobacteria growth indicator tube mgit for drug susceptibility testing of Mycobacterium tuberculosis isolates from clinical specimens. Clin Microbiol Infect 1999;5:227-30.

23. Borges-Argáez R, Canche-Chay CI, Peña-Rodríguez LM, Said-Fernández S, Molina-Salinas GM. Antimicrobial activity of Diospyros anisandra. Fitoterapia 2007;78:370-2.

24. Gautam R, Saklani A, Jachak SM. Indian medicinal plants as a source of antimycobacterial agents. J Ethnopharmacol 2007;110:200-34.

25. Okunade AL, Elvin-Lewis MP, Lewis WH. Natural antimycobacterial metabolites: Current status. Phytochemistry 2004;65:1017-32.

26. Camacho-Corona Mdel R, Ramírez-Cabrera MA, Santiago OG, GarzaGonzález E, Palacios Ide P, Luna-Herrera J, et al. Activity against drug resistant-tuberculosis strains of plants used in Mexican traditional medicine to treat tuberculosis and other respiratory diseases. Phytother Res 2008;22:82-5

27. Tosun F, Kizlay CA, Sener B, Vural M, Palittapongarnpim P. Antimycobacterial screening of some Turkish plants. J Ethnopharmacol 2004:95:273-5.

28. Mohamad S, Zin NM, Wahab HA, Ibrahim P, Sulaiman SF, Zahariluddin AS, et al. Antituberculosis potential of some ethnobotanically selected Malaysian plants. J Ethnopharmacol 2011;133:1021-6.

29. Tekwu EM, Askun T, Kuete V, Nkengfack AE, Nyasse B, Etoa FX, et al. Antibacterial activity of selected Cameroonian dietary spices ethno-medically used against strains of Mycobacterium tuberculosis. J Ethnopharmacol 2012;142:374-82.

30. Kuete V. Potential of Cameroonian plants and derived products against microbial infections: A review. Planta Med 2010;76:1479-91

31. Irianti T, Puspitasari A, Machwiyyah L, Rabbani HR. The activity of radical scavenging Of 2, 2-Diphenyl-1-Pycrilhydrazil (DPPH) by ethanolic extracts of mengkudu leaves (Morinda citrifolia L.), brotowali stem (Tinospora crispa L.), its water fraction and its hydrolized fraction. Tradit Med J 2016;20:140-8.

32. Koay Y, Koay F. A review of the secondary metabolites and biological activities of "Tinospora crispa" (Menispermaceae). Trop J Pharm Res 2013;12:641-9.

33. García A, Bocanegra-García V, Palma-Nicolás JP, Rivera G. Recent advances in antitubercular natural products. Eur $\mathrm{J}$ Med Chem 2012;49:1-23. 